\title{
Redesain Pasar UMKM dengan Pendekatan Kontekstual
}

\author{
Hertrisna Ayu Dahlima dan Andy Mappajaya \\ Departemen Arsitektur, Fakultas Arsitektur Desain dan Perencanaan, Institut Teknologi Sepuluh Nopember (ITS) \\ e-mail:mappajaya@arch.its.ac.id
}

\begin{abstract}
Abstrak-Fenomena UMKM dapat dilihat pada kampungkampung di Surabaya, salah satunya adalah kampung Genteng Candirejo. Identitas Genteng sebagai Pusat Oleh-oleh Surabaya menjadikan kawasan ini memiliki potensi untuk mewadahi dan menjadi pertahanan UMKM Surabaya. Redesain Pasar Genteng menjadi respon arsitektural dalam perencanaan keberlanjutan UKM Surabaya. Redesain Pasar Genteng dalam perancangan ini menggunakan metoda penggabungan fungsi bangunan/ Mixed Use. Yaitu dengan memaksimalkan fungsi komersial yang dihubungkan dengan fungsi penunjang untuk keberlanjutan UMKM Surabaya. Pendekatan yang digunakan ialah Pendekatan Kontekstual sebagaimana perancangan merupakan respon dari konteks kampung UMKM sekitar. Selain itu konsep Mix Use digunakan sebagai pendekatan Urban Katalis untuk memaksimalkan fungsi bangunan sekaligus sebagai ikon/ landmark kawasan. Hasil dari rancangan merupakan Pasar yang memunculkan fungsi-fungsi baru dengan mempertahankan fungsi yang sudah ada. Rancangan juga memperbaiki aspek kenyamanan pasar dari desain yang sebelumnya.
\end{abstract}

Kata Kunci-UMKM, Redesain Pasar, Mixed Use, Kontekstual, Urban Katalis.

\section{PENDAHULUAN}

$\mathrm{S}_{\mathrm{n}}^{\mathrm{B}}$ EKTOR Usaha Mikro, Kecil dan Menengah (UMKM) merupakan salah satu bagian penting dalam perekonomian dan pembangunan nasional. Mengingat UMKM sebagai penggerak perekonomian dan pembangunan nasional maka perlu dilakukan strategi dalam upaya pemberdayaan pada sektor tersebut. Kota Surabaya tercatat sebagai kota yang paling lama melaksanakan program perbaikan kampung di Indonesia. Sejak beberapa tahun ini karena kelembagaan di kampung umumnya sudah semakin baik pelaksanaan KIP selanjutnya ditekankan pada pengembangan sumber daya manusia dalam bentuk pengembangan kampung unggul dengan berbagai jenis produk UKM home industry [1].

Permasalahan yang akan diangkat adalah bagaimanakah fenomena UMKM meningkatkan ekonomi rakyat. Apa wadah arsitekturaal yang sesuai sebagai respon Kampung UMKM yang membutuhkan rencana keberlanjutan jangka panjang ?

Bagaimana mewadahi potensi produk kampung unggulan dengan keterkaitannya terhadap pemukiman warga yang berperan sebagai household based enterprise, serta pengembangan ketrampilan pemeran dalam ber UMKM dan berinovasi mengolah produk baru.

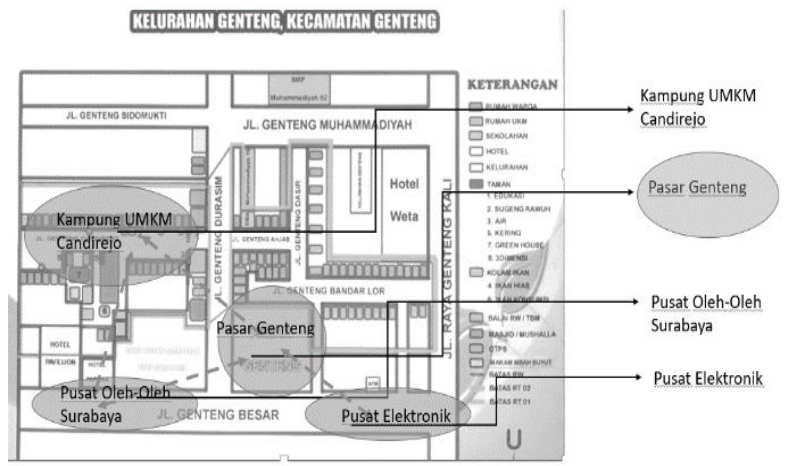

Gambar 1. Peta Kelurahan Genteng.

Dengan berubahnya wajah kampung Genteng Candirejo yang bernilai ekonomis dan memiliki identitas baru sebagai kampung UMKM dapat dikaitkan dengan keberadaan Pasar Genteng serta Identitas Genteng sebagai pusat oleh oleh Surabaya. Dari ketiga variable identitas Genteng tersebut yaitu: kampung Candirejo, Pasar Genteng dan Pusat oleh-oleh Surabaya, perancang memiliki tujuan untuk mengintegrasikan berbagai potensi tersebut dengan meredisain Pasar Genteng sebagai fokusan rancangan sebagai respon dari fenomena lingkungan sekitar agar saling memberi dampak positif baik dari segi ekonomi, sosial, budaya dan lingkungan.

Tujuan dari perancangan Re-desain Pasar Genteng ialah :Pasar yang memiliki nilai lebih dari sekedar pasar pada umumnya , tanpa menghilangkan ciri karakter pasar tradisional. Pasar yang berkemampuan bekerjasama dalam pengadaan atau produksi dengan pihak atau pelaku bisnis lainnya;Pasar yang berkemampuan membiayai pemeliharaan dan perawatan secara mandiri; Pasar yang berkemampuan menarik pengunjung/turis dari kota-kota lain: Rencanakan pasar tradisional, yang dapat bergabung dengan fungsi lain agar dapat menarik kaum muda perkotaan/ sebagai urban katalis; Dalam konsep perancangan Redesain Pasar Genteng ini memiliki tiga fokusan kriteria rancang yaitu :Kenyamanan Bangunan, komunikasi dan Interaksi, keunikan Desain

Redesain Pasar Genteng dalam perancangan ini bukan sekedar memperbaiki kondisi pasar namun juga memiliki tujuan menambahkan nilai tambah pada Pasar. Bangunan dirancang dengan memunculkan fungsi-fungsi baru yang dapat mendukung rencana keberlanjutan dari eksistensi Pasar 
Genteng kedepan.

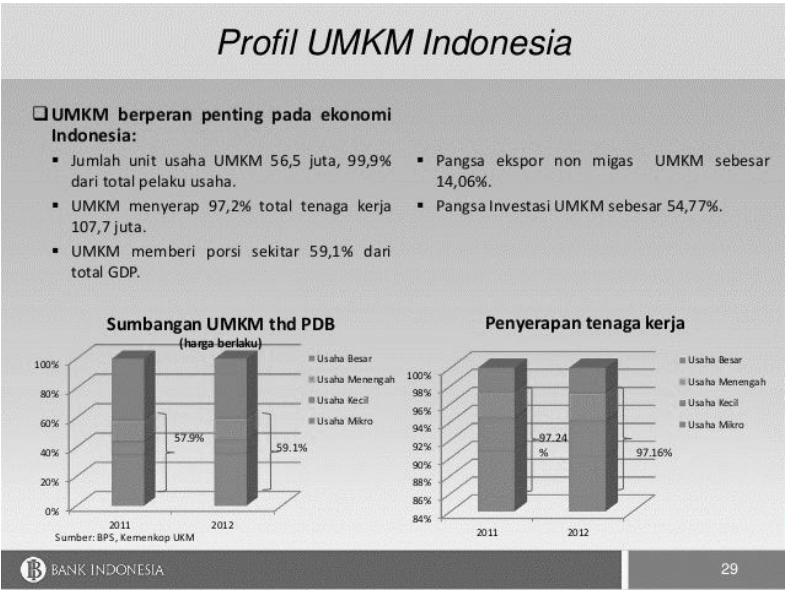

Gambar 2. Profil UMKM Indonesia.

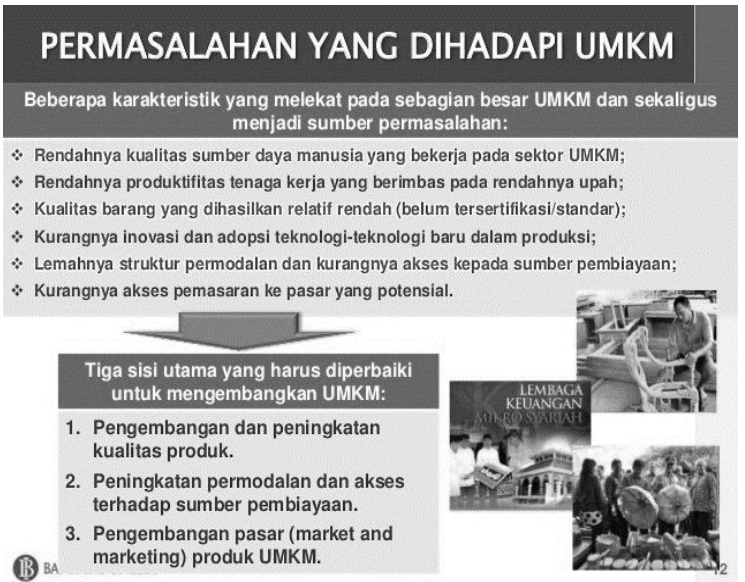

Gambar 3. Permasalahan UMKM.

Fungsi bangunan merupakan bangunan Pasar dengan konsep mix use, selain pasar tradisional sebagaimana umumnya diantaranya terdapat sentra UKM produk-produk lokal , Pasar Khusus yang menjual hasil dari UKM sekaligus memunculkan fungsi-fungsi baru berupa pusat pelatihan ukm, coworking space, dan penginapan untuk pelaku bisnis UKM. Fungsi-fungsi baru dimunculkan sebagai nilai tambah dari Pasar Genteng yang memiliki potensi menjadi pusat pengembangan produk UKM Surabaya.

\section{METODA PERANCANGAN}

Pendekatan desain yang akan menjadi fokusan dalam redesain Pasar Genteng ini menggunakan pendekatan kontekstual, sesuai dengan tujuan perancang yang ingin mengintegrasikan Pasar Genteng dengan kondisi dan keadaan terkini terkait lingkungan sekitar yaitu adanya fenomena kampung UMKM yang sedang berkembang dan membutuhkan rencana keberlanjutan.

Arsitektur kontekstual adalah sebuah metode perancangan yang mengkaitkan dan menyelaraskan bangunan baru dengan karakteristik lingkungan sekitar. Dengan pemahaman bahwa

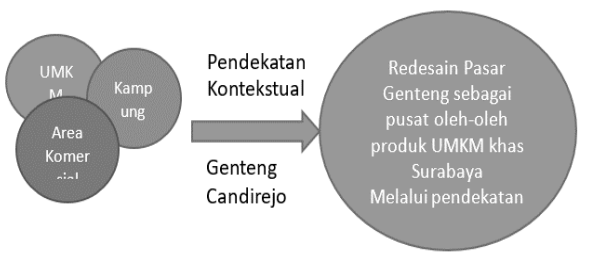

Gambar 4. Respon arsitektural.

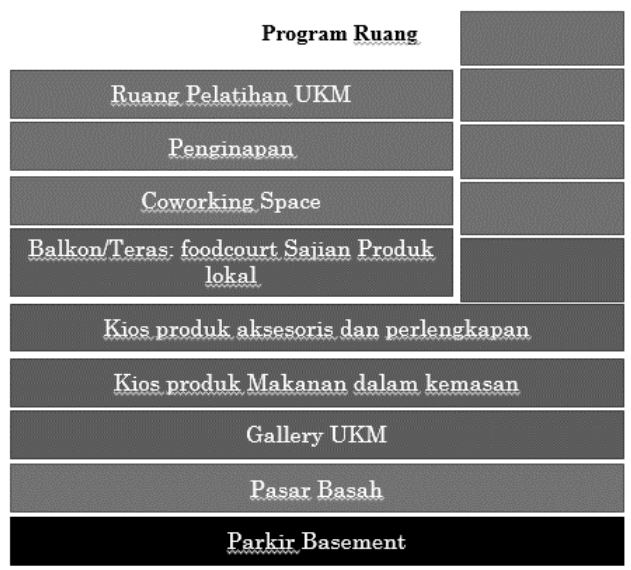

Gambar 5. Program ruang.
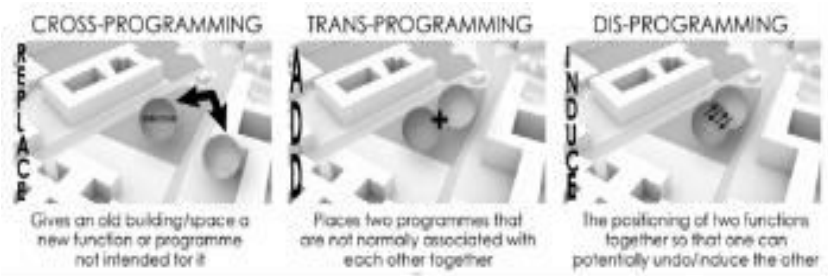

Gambar 6. Metoda desain Bernard Tschumi.

arsitektur kontekstual sebagai arsitektur yang memenuhi konteks, maka dapat disimpulkan bahwa definisi yang terangkum arsitektur kontekstual adalah arsitektur yang hadir dengan memperhatikan dan memadukan elemen-elemen yang ada disekitar (fisik maupun non-fisik) sehingga memberikan makna bagi linkungan sekitar sebagai suatu kesatuan ruang [2].

Salah satu tujuan dari perancangan ini ialah menghadirkan karakter dari Pasar Genteng sendiri yang menggunakan pendekatan kontekstual yaitu konteks isu ciri khas Surabaya. Sehingga dibutuhkan suatu metoda untuk menghadirkan makna dalam bangunan yang diharapkan dapat memberikan karakter tersendiri dari Pasar Genteng.

Metode yang digunakan dalam menghadirkan makna dalam arsitektur dapat menggunakan teori Semiotika. Semiotika (semiotics) berasal dari bahasa Yunani "semeion" yang berarti tanda. Tanda-tanda tersebut menyampaikan suatu informasi sehingga bersifat komunikatif, mampu menggantikan suatu yang lain (stand for something else) yang dapat dipikirkan atau dibayangkan [3].

Metoda program ruang yang digunakan merupakan suatu metoda desain yang menerapkan prinsip fleksibilitas ruang 


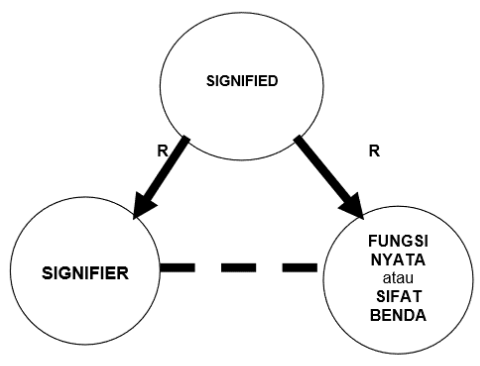

$R=$ Relation

Gambar 7. Metoda semiotic

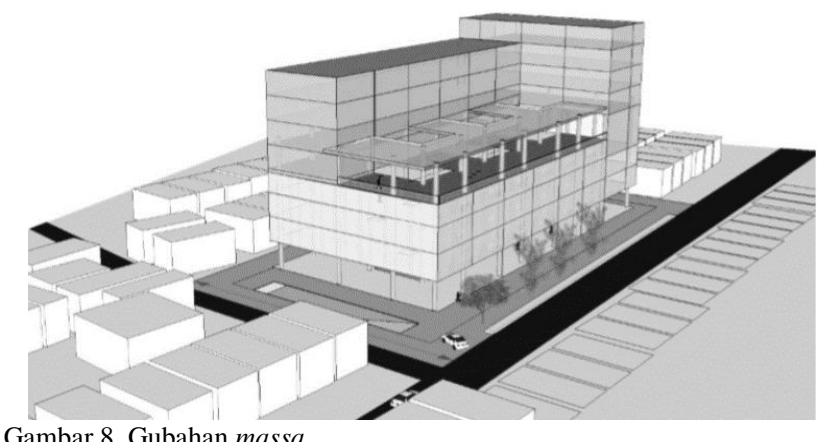

Gambar 8. Gubahan massa.

dan waktu. Prinsip Fleksibilitas ruang dan waktu digunakan dalam merancang kebutuhan umum dari definisi ruang pasar itu sendiri sekaligus sebagai respon dari fenomena konteks lingkungan sekitar yang diamati. Dalam perancangan revitalisasi Pasar Genteng akan memungkinkan fungsi ruang baru selain pasar yang terintegrasi dengan konteks kampung UMKM yang berkembang disana. Metoda yang digunakan menggunakan teori programming Bernard Tscumi yaitu teori disjunction. Teori disjunction menghadapkan arsitektur pada ketidakjelasan ruang dan kegunaannya. Hal yang sangat bertolak belakang pada ideologi arsitektur klasik dan modern, dimana arsitektur dianggap sebagai sesuatu yang stabil, solid, dan landasan untuk menciptakan suatu bentuk yang permanen.

\section{HASIL PERANCANGAN}

Gubahan massa merupakan keputusan desain berdasar konteks fungsi serta kenyamanan. Pada tumpukan massa bawah merupakan area market, sedangkan kedua massa lainnya pada bagian atas merupakan area fungsi lain, berupa pusat pelatihan UMKM, Coworking Space dan penginapan.

Dalam merespon konteks pasar basah yang berada di lantai dasar, maka disediakan parker motor pada bagian depan site. Terdapat offset lahan dari massa bangunan sebagai ruang untuk loading barang melalui belakang. Selain itu TPS berada pada ujung timur belakang agar tidak mengganggu aktivitas jalan samping.

Metode semiotic diterapkan dalam penggunaan ornamen anyaman yang dapat dimaknai dari symbol keuletan UMKM itu sendiri. Sebagaimana bangunan merupakan respon dari konteks UMKM. Tangga darurat selain berfungsi sebagai

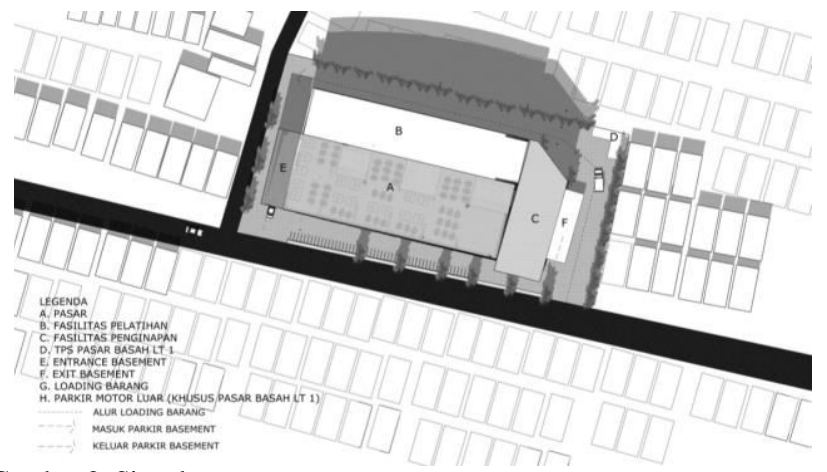

Gambar 9. Site plan.

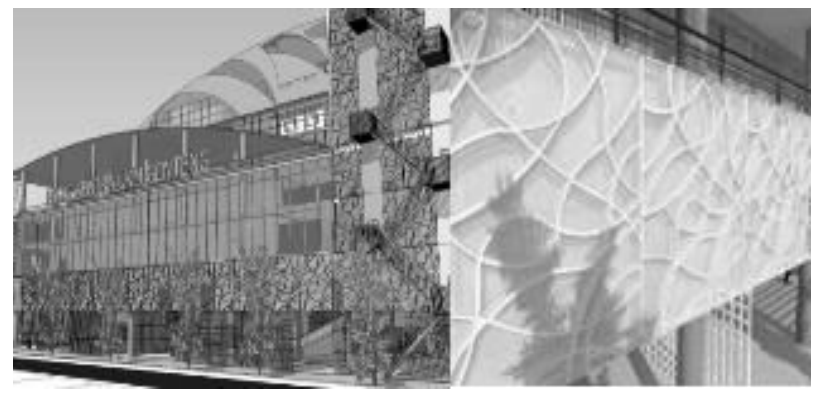

Gambar 10. Ornamen fasad.

fungsi utamanya, juga digunakan sebagai elemen fasad. Sehingga integrasi antara aspek fungsi dan estetika terlihat pada bangunan Pasar Genteng.

Area foodcourt outdoor yang terdapat di lantai 5 dengan penghawaan alami. Berdasar survey pengamatan pada lantai 4 sudah mendapatkan angin yang cukup kencang. Terdapat pada lantai 5 sehingga mudah dijangkau dari area market lantai bawah maupun area pusat pelatihan lantai atas.

Terdapat lobby pemisah antara fungsi ruang penginapan dan fasilitas kelas pelatihan UKM maupun coworking space. (gambar).

Coworking Space semaksimal mungkin memanfaatkan pencahayaan alami, untuk mencapai kenyamanan visual. Untuk mencapai produktifitas pengguna ruangan, kenyamanan visual dan suhu ruangan diutamakan pada fungsi ruang ini. Sehingga penghawaan ruang menggunakan AC.

Sirkulasi sirkular dengan konsep atrium, memiliki banyak keuntungan bagi kenyamanan pengunjung. Kemudahan menjangkau semua kios serta kenyamanan visual saat berbelanja.

Berdasarkan Satuan Ruang Parkir (SRP) pusat perdagangan /100m2, maka didapat total kebutuhan parker Pasar Genteng memerlukan minimal 60 unit mobil harus tertampung dalam bangunan. Sehingga dibutuhkan 2 basement untuk memenuhi seluruh kebutuhan parker.

Sistem penghawaan pada lantai dasar yang merupakan fungsi pasar basah, menggunakan penghawaan alami. Sedangkan penghawaan untuk kios, ruko, dan aktivitas fungsi lain menggunakan penghawaan AC. Sedangkan untuk area foodcourt lt 5 , berupa teras kota dengan konsep terbuka. 


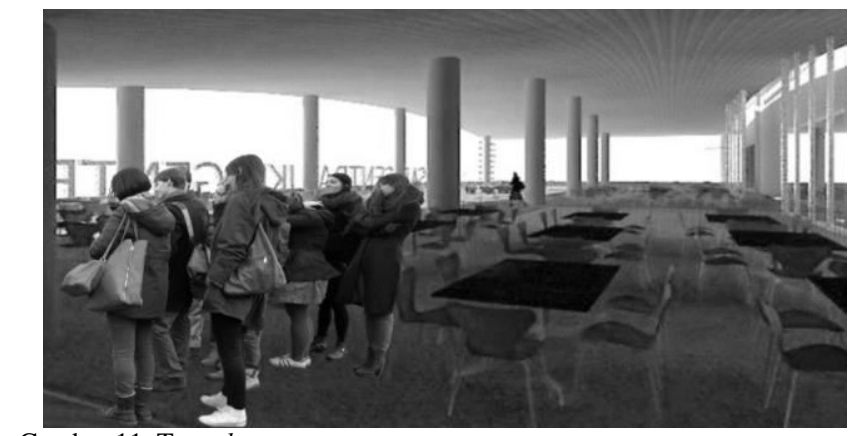

Gambar 11. Teras kota.

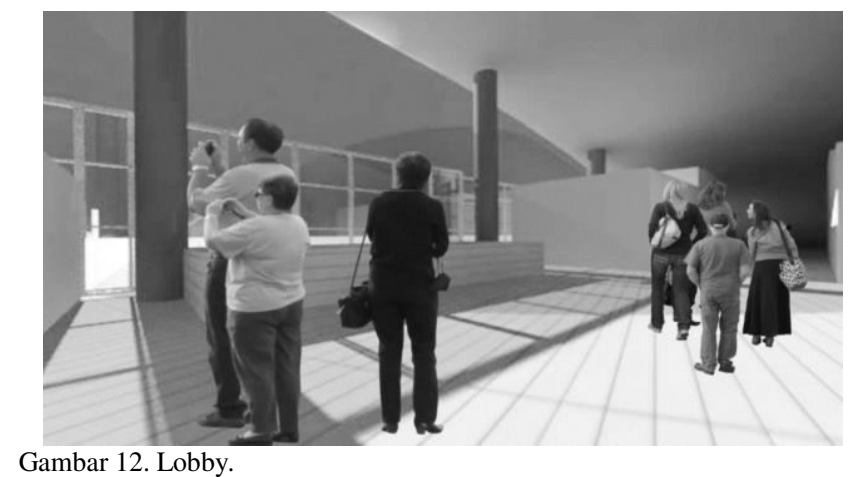

Menggunakan system struktur plat kolom balok dengan bentang lebar antar kolom $10 \mathrm{~m}$. Bentang yang luas ini untuk memaksimalkan fungsi ruang serta kenyamanan sirkulasi di dalam ruang. Struktur atap menggunakan atap melengkung dengan struktur rangka baja. Terdapat shaft pada tiap kamar penginapan yang akan disalurkan horizontal pada shat utama berdekatan dengan restroom.

Sebagian besar fasad bangunan merupakan elemen kaca , dengan jenis kaca tergantung kebutuhan dan fungsi ruang. Untuk ruang dengan fungsi pasar dan fasilitas umum menggunakan kaca jenis laminated yang memiliki kemampunan uv protection. Sedangkan untuk fungsi kebutuhan ruang penginapan dibutuhkan kaca dengan jenis double glass yang memiliki kelebihan kedap suara dan dapat menjaga kestabilan suhu.

Pengamat akan merasakan kesan ruangan yang "ramai tapi teratur" dikarenakan batang-batang space frame yang salingsilang sengaja diekspos dan menjadi elemen estetika utama. Dengan demikian warna yang dihadirkan hanya elemen warna monokrom hitam dan putih saja untuk menyederhanakan keramaian dari batang-batang space frame. (Gambar 7)

\section{KESIMPULAN}

Redesain pasar Genteng merupakan respon dari isu UMKM yang diamati penulis. Dalam perancangan ini digunakan pendekatan kontekstual yang diwujudkan dalam penentuan setiap keputusan desain. Terkait bagaimana mencapai tujuan yang merujuk pada isu maupun dalam menangani masalah yang ada pada pasar itu sendiri. Selain pendekatan kontekstual

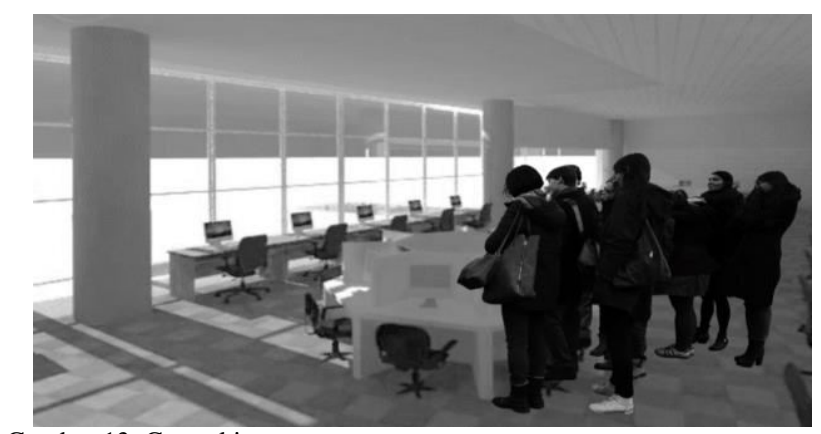

Gambar 13. Coworking space.

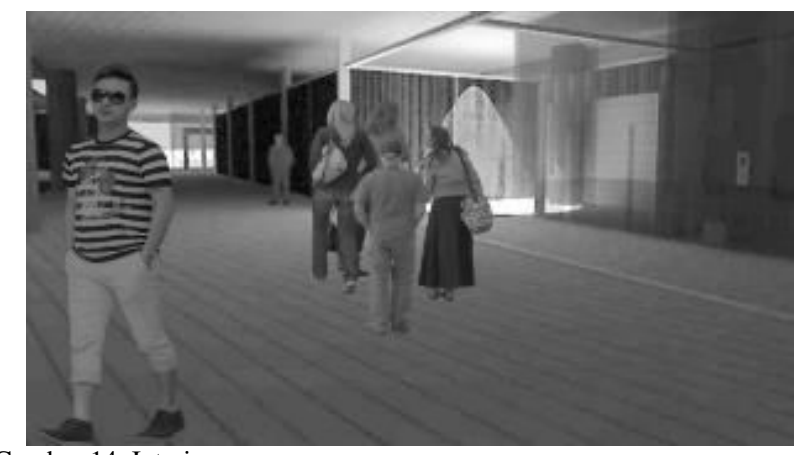

Gambar 14. Interiro pasar.

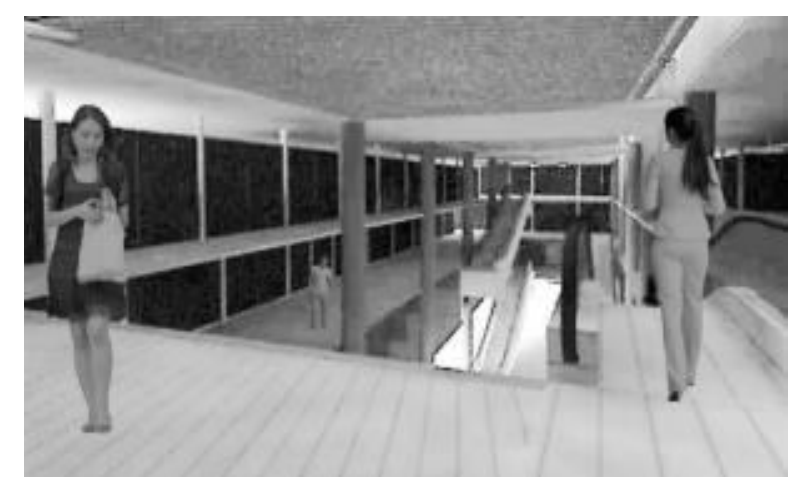

Gambar 15. Sirkulasi pasar.

dibutuhkan pendekatan lain yang mendukung untuk mencapai tujuan desain, dalam hal ini penulis menggunakan pendekatan urban catalys dimana pasar genteng ini diharapkan dapat menjadi penggerak aktivitas urban bagi warga kota. Aktivitas urban ini tentu saja berkaitan dengan isu UMK yang menjadi fokusan penulis. Dalam desain ini diwujudkan penulis dengan penambahan fungsi penggerak aktivitas urban ialah, terdapatnya gallery UKM, coworking space dan pusat pelatihan UKM. Untuk mencapai tujuan redesain Pasar Genteng ini digunakan metoda pemograman Bernard Tschumi tentang teori disjunction. Dimana sebuah fungsi bangunan dapat dikombinasikan dengan fungsi-fungsi yang lain. Selain itu, salah satu tujuan desain yang lain ialah menjadikan Pasar Genteng sebagai ikon dan Landmark kawasan UKM Surabaya. Pada rancangan ini diwujudkan dengan menggunakan metode semiotic, yaitu dengan memberikan makna pada bangunan, baik dalam fisik maupun fungsi. Metode ini diwujudkan dengan tampilan fasad yang 
menganyam yaitu memiliki symbol dan makna dari keuletan UMKM. Semiotic dalam pewujudan fungsi ialah terdapatnya teras kota pada bangunan sebagai landmark kawasan.
Pemerintah Kota Surabaya, Kampung Surabaya Menuju Abad 21, Kajian Penataan dan Revitalisasi Kampung di Surabaya. 2012.

Y. F. Limpong and J. Van Rate, "Arsitektur kontekstual dengan pendekatan site dan budaya.".

B. Tschumi, Architecture and Disjunction. England: MIT Press, 1996.

DAFTAR PUSTAKA 